\title{
O CARÁTER TRANSDISCIPLINAR DA CRIATIVIDADE E DO LETRAMENTO: PERSPECTIVAS À LUZ DO PENSAMENTO COMPLEXO
}

\author{
Elza Rodrigues Barbosa Peixoto \\ Universidade Federal do Tocantins - UFT (Brasil) \\ elza.peixoto21@gmail.com · https://orcid.org/0000-0001-9663-008X \\ Maria José de Pinho \\ Universidade Federal do Tocantins - UFT (Brasil) \\ mjpgon@mail.uft.edu.br · https://orcid.org/0000-0002-2411-6580
}

\begin{abstract}
Resumo: Este artigo apresenta o recorte de uma investigação de doutorado sobre as interações nas práticas de letramento em contexto escolar e visa ampliar as discussões sobre o caráter transdisciplinar dessas práticas. Teve como objetivo geral analisar as práticas pedagógicas realizadas pela Escola Paroquial Sagrado Coração de Jesus, procurando compreender as implicações do vínculo professor e aluno, no contexto das interações nas práticas de letramento, em aulas de Língua Portuguesa, sob o olhar da criatividade e do pensamento complexo. Para atender ao objetivo proposto, este estudo ancorou-se na proposição de uma reforma do pensamento/pensamento complexo (Morin, 2000, 2001, 2005), na transdisciplinaridade (Nicolescu, 2001), pelos estudos da criatividade (Torre, 2005) e (Moraes, 2015). Os outros fios que juntamos nessa tessitura estão vinculados às práticas de letramento escolar, cujo caminho de investigação trilham pelos Novos Estudos do Letramento (NEL), fundamentados em Street (2014), Barton e Ivanic (2000), Rojo (2009), Soares (2003) e Kleiman (2006), principalmente. O caminho metodológico percorrido foi o estudo de caso, de caráter exploratório, apoiado na abordagem qualitativo-interpretativa, tendo como instrumento de coleta de dados a entrevista semiestruturada, observação direta, gravação de aulas e análise documental. Nos resultados, evidenciou-se que a presença de forte afetividade não era meramente intuitiva a depender do perfil dos professores, mas fazia parte, intencionalmente, do desenvolvimento de um trabalho centrado em despertar a confiança, elevar a autoestima, resgatar os valores humanos, ou seja, estabelecer no trajeto, vínculos pela empatia e promove o necessário diálogo.
\end{abstract}

Palavras-chaves: Pensamento complexo, Transdisciplinaridade, Criatividade, Letramento.

\section{EL CARÁCTER TRANSDISCIPLINAR DE LA CREATIVIDAD Y DEL ALFABETIZACIÓN: PERSPECTIVAS A LA LUZ DEL PENSAMIENTO COMPLEJO}

\footnotetext{
Resumen: Este artículo presenta el recorte de una investigación de doctorado sobre las interacciones en las prácticas de alfabetización en el contexto escolar y busca ampliar las discusiones sobre el carácter transdisciplinar de esas prácticas. Tuvo como objetivo general analizar las prácticas pedagógicas realizadas por la Escuela Parroquial Sagrado Corazón de Jesús, buscando comprender las implicaciones del vínculo entre profesor y alumno, bajo la mirada de la creatividad y del pensamiento complejo. Para alcanzar el objetivo propuesto, este estudio se fundamentó en la proposición de la reforma del pensamiento / pensamiento complejo (Morin, 2000, 2001, 2005), en la transdisciplinariedad (Nicolescu, 2001), por los estudios de la creatividad (Torre, 2005), (Moraes, 20015). Los otros hilos que juntamos en esta tesitura están vinculados a las prácticas de alfbetización, cuyo camino de investigación trillan por los Novos Estudios del Letramiento (NEL), fundamentados en Street (2014), Barton e Ivanic
} 
(2000), Rojo (2009), Soares (2003) Kleiman (2006), principalmente. El camino metodológico recorrido fue el estudio de caso, de carácter exploratorio, apoyado en el enfoque cualitativo-interpretativo, teniendo como instrumento de colecta de datos la entrevista semiestructurada, observación directa, grabación de clases y análisis de documentos. En los resultados se evidenció que la presencia de una fuerte afectividad no era meramente intuitiva dependiendo del perfil del profesor, sino que hacía parte, intencionalmente, del desarrollo de un trabajo centrado en despertar la confianza, elevar la autoestima, rescatar los valores humanos, o sea, establecer en el recorrido, vínculos de empatía y promover el necesario diálogo.

Palabras clave: Pensamiento complejo, Transdisciplinariedad, Creatividad, Alfabetización.

\title{
THE TRANSDISCIPLINARY CHARACTER OF CREATIVITY AND LETTERING: PERSPECTIVES IN THE LIGHT OF COMPLEX THINKING
}

\begin{abstract}
This paper shows the clipping of a doctorate research about the interactions in literacy practices in school context and aims increeasing the discussions about the transdisciplinary nature of these practices. It has a general objective was to analyze the pedagogical practices performed by Escola Sagrado Coração de Jesus, trying to understand the implications of the connection between teacher and student, in the interactions context of the literacy practices, in Portuguese language classes, under the perspective of creativity and complex thinking. In order to achieve the proposed objective, this study has anchored in the proposal of a thinking reform/ complex thinking (Morin, 2000, 2001, 2005), in transdisciplinarity (Nicolescu, 2001), in the creativity study (Torre, 2005), (Moraes, 2015). The other wires that we joined in this texture are linked to the school literacy practices, which path of investigation treads by the New Studies of Literacy (NSL), reasoned on Street (2014), Barton and Ivanic (2000) and Kleiman (2006), mainly. The methodological path taken was the case report of exploratory nature, supported by the qualitative-interpretative approach, with the semistructured interview, as a data collection instrument direct observation, class recording and documental analyze. In the result, it was clear that the presence of strong affectivity wasn't merely intuitive depending on the teachers' profile, but it was a part intentionally of a work developmente focused on awakning the trust, elevatin selfesteem, rescuing human values, I mean, establishing in the path connection through the empathy and promoting the necessary dialogue.
\end{abstract}

Keywords: Complex thinking, Transdisciplinarity, Creativity, Literacy.

\section{Introdução}

Os desafios do nosso tempo nos colocam diante de novos modos de ser e estar nas escolas, nas famílias e nas instituições. Essas questões vêm sendo discutidas no cenário educacional há algum tempo por diferentes áreas. Nesse artigo, nosso objetivo é trazer à discussão aspectos que emergem da articulação entre a criatividade e o letramento em uma perspectiva transdisciplinar, observados no cotidiano escolar e analisados à luz do pensamento complexo.

Essa proposta de articulação é parte integrante de nossa tese doutoral intitulada: Criatividade e Letramento escolar: Um estudo de caso à luz do pensamento complexo. Essa pesquisa vinculou-se à linha práticas discursivas em contextos de formação, do Programa de Pós-graduação em Letras, da Universidade Federal do 
Tocantins - UFT, assim como ao projeto de pesquisa Escolas Criativas: reconhecer e difundir o potencial inovador e criativo da escola do século XXI, coordenado pela Professora Doutora Maria José de Pinho, pertencente à Rede Internacional de Escolas Criativas - RIEC.

Desta forma, pode suscitar, logo de saída, algumas questões que guiam essa análise em recorte. São elas: Quais os pressupostos considerados para o alinhamento epistemológico que concebemos? Como esses aspectos podem contribuir para uma articulação tanto da criatividade como do letramento estudados a partir das mesmas relações, em destaque, o caráter interacional na dimensão subjetiva das relações que condicionam e potencializam o envolvimento e desenvolvimento de professores e alunos?

Acreditamos que uma análise dessa natureza nos permite revelar a importante relação entre letramento e criatividade em outro nível, no qual o foco não esteja exclusivamente no objeto de aprendizagem, mas nos sujeitos em sua subjetividade e intersubjetividade, na forma como os participantes constroem sentido para os objetos a partir do modo de interação estabelecido. Esse é um dos aspectos que torna esse estudo significativamente relevante, pois trabalhar as práticas de letramento, sob o olhar da criatividade e do pensamento complexo, amplia o campo conceitual e torna possível um olhar mais sensível nas relações de interdependência que configuram o ensino e a aprendizagem e os vínculos criados pelos seus principais atores, professor e aluno.

Ao alocarmos este estudo em solo transdisciplinar, propusemos como objetivo geral analisar as práticas pedagógicas realizadas pela escola pesquisada, procurando compreender as implicações do vínculo professor e aluno, no contexto das interações nas práticas de letramento, em aulas de Língua Portuguesa, sob o olhar da criatividade e do pensamento complexo.

Com base nessa relação de prática docente, construída no cotidiano escolar, buscamos relevância na apresentação de uma investigação que não fosse apenas caracterizadora ou descritora de práticas ou procedimentos, mas que fosse promotora de um novo olhar, que contribuísse efetivamente para ações (trans)formadoras e um pensar complexo no contexto escolar, a partir da compreensão de suas próprias ações cotidianas e iniciativas de um fazer integrado.

A escola como espaço de construção do saber, embora não seja o único espaço onde as práticas de letramento se constituem, funcionam como eixo que engendra nossa problemática, pois são nesses espaços institucionalizados que estão delegadas as responsabilidades pela sistematização, difusão e aprimoramento das práticas de leitura e escrita em nosso tempo. Traçar um mapeamento interno dessas práticas, atrelados aos modos de interação construídos na relação entre professores e alunos é apresentar ao leitor uma cena pelos diversos olhares e perspectivas nela construída. Dessa forma, ao promover esse estudo, estamos conjuntamente a tantas vozes que escolhemos para compor os registros dessas vivências, construindo um caminho de pesquisa que faz emergir significados "conflitantes e paradoxais" conforme nos afirma Bunzen (2009).

Investigar no contexto apresentado, perpassa pela compreensão da realidade complexa que envolve a educação e que novas formas de pensá-la são necessárias para responder às demandas de nosso tempo. Investigar o ser em desenvolvimento, mesmo que em sua parcela escolar, requer uma perspectiva multirreferencial e multidimensional em sua complexidade de análise. 
O que pretendemos destacar neste artigo, aproveitando desses questionamentos e dessa construção teórica, é a importância da compreensão dessas múltiplas realidades, que são manifestadas a partir do que cada sujeito é capaz de ver, interpretar e relacionar, dentro de sua capacidade de interagir com outros sujeitos e com a realidade, e refletir como isso se atualiza no contexto da escola.

$\mathrm{Na}$ escola não é incomum o julgamento da aprendizagem do aluno pela perspectiva do ensinar do professor, considerando o conhecimento por um único nível de realidade. $\mathrm{O}$ fato de o professor ministrar uma boa aula, não significa que houve, consequentemente, uma boa aprendizagem, dadas às muitas variáveis que estão envolvidas nesse processo.

Isso reforça a tese de que não basta uma formação docente voltada à uma metodologia que oriente para transdisciplinaridade, pois para que esta seja uma realidade, há a necessidade de uma transformação primeiramente do sujeito, professor, que possa olhar o outro sem o peso da universalização de verdades ou dos condicionamentos produzidos pela cultura que nos forma; mas ao contrário, é preciso atitudes renovadas para lidar com a multiplicidade do ser e a diversidade do modo de pensar e conceber a realidade, mas para isso é preciso sensibilidade.

Esse é um processo difícil, especialmente quando uma grande parte do professorado concebe o mundo a partir de seus referenciais teóricos tradicionais, linear, racionalista, que acaba por fazer prevalecer a objetividade à subjetividade. Por isso, não basta simples formação, se o sujeito não for afetado pela mudança de consciência.

Vivenciar os conceitos teóricos na prática significa a assimilação deles pela emoção, manifestando-os nas atitudes diárias. Portanto, os obstáculos são internos e externos: as nossas próprias atitudes e a organização da sociedade que, por sua vez, cobra o modo de pensar e fazer por meio de normas, regras e valores (Santos e Sommerman, 2014, p. 91-92).

Sem a interação ser-saber, sujeito-conhecimento, sujeito e cultura, vai se distanciando a virada paradigmática, e solidificando a visão de que o saber se situa fora do sujeito. É no sentido oposto que vai a transdisciplinaridade, onde "todo conhecimento é fruto de processos interpretativos, auto-organizadores e criativos por parte do sujeito que aprende" (Moraes, 2008, p. 68). Essa compreensão nos ajuda a ressignificar as nossas práticas, ampliando as competências docentes para além da instrumentalização que é necessária, mas que precisa avançar na direção do desenvolvimento e da consciência humana.

Sendo assim, uma educação pelos princípios da transdisciplinaridade é aquela que olha a partir da lógica do terceiro incluído, com abertura porque, como afirma Morin (2003, p. 45), "o conhecimento fragmentado impede a compreensão da totalidade, e da complexidade, não permitindo apreender o que está tecido junto". Nessa nova lógica, que considera que o observador afeta e é afetado pelo objeto observado, da mesma maneira o ensino e a aprendizagem se entretecem na trama das interações professor e aluno, isso nos impele a incluir as duas perspectivas em graus de importância: como se ensina e como se aprende.

Ao descortinar esse cenário, vamos traçando uma rota que vislumbra uma caminhada de estudos e investigação, no qual a criatividade vem assumindo um complexo que articula habilidades, atitudes, ações, formas de pensamento e de atuação em uma perspectiva integral, levando em consideração seus de valores, utilidades e 
inovação. Desta forma, o nosso olhar sobre essas perspectivas apresentadas buscam por um enfoque de trato mais integral do tema e, embora outras perspectivas também caminhem nessa direção, a rota que assumimos para trilhar em nossa análise passa pela compreensão da criatividade como um bem social e de futuro (Torre, 2005) e, por isso mesmo, reflete um fenômeno de natureza complexa e transdisciplinar, fruto de uma tessitura relacional que se materializa "a partir das atividades desenvolvidas e das relações emergentes no encontro do polo subjetivo com o polo objetivo, representado pela realidade" (Moraes, 2015, p. 176 ).

Dentro de um panorama que ainda pode-se considerar inicial na busca de estudos que abordem a criatividade dentro de uma visão mais integral, tomaremos como rota de percurso em nossa investigação sobre criatividade e letramento escolar a perspectiva apontada na obra de Moraes e Navas (2015), Transdisciplinaridade, criatividade e educação: fundamentos ontológicos e epistemológicos. Obra que traz sua contribuição, promovendo uma ampliação teórica no rumo dos fundamentos ontológicos e epistemológicos da criatividade no campo da educação. A autora considera que "necessitamos de uma educação integral transdisciplinar nutrida por novas visões conceituais capazes de promoverem um pensamento que não mais fragmente, reduza ou dissocie a realidade" (Moraes e Navas, 2015, p. 20).

Assim como afirma Moraes (2003, p. 167) "este momento revela-se de grande e extrema oportunidade para se catalisar mudanças educacionais importantes, transformar a maneira como pensamos e concebemos a escola, a educação e a própria vida."

Pautada no conceito de que educar para a criatividade requer uma reforma nos processos de construção do pensamento e reorganização do conhecimento (Morin, 2000), e longe de certezas de qual a melhor trilha para se alcançar esse objetivo, vamos firmando nossos passos no devir das relações sujeito/objeto, sujeito/meio e contexto e sujeito/sujeito já que são as relações abertas que nos convidam a romper as fronteiras "sabendo que todo e qualquer objeto jamais poderá ficar encerrado em um conceito ou aprisionado em um discurso" (Moraes, 2015, p. 107).

Tal como abordado nos princípios que podem nos levar a um pensar complexo, buscamos nos fundamentos da Rede de Escolas Criativas, os norteadores para analisar as práticas de letramento da escola pesquisada, assumindo como lentes da realidade observada, a perspectiva complexa e transdisciplinar da criatividade (Moraes, 2015).

Ao associar essa noção vamos compreendendo e dando corpo ao conceito de "escola criativa" de que nos fala Moraes (2015, p. 123), apontando que a criatividade é mais que um traço psicobiológico, sendo sobretudo uma característica "emergente" no sentido de possibilitar "dar respostas novas a velhos problemas que podem também ser repensados de um novo modo". Dentro dessa perspectiva da criatividade na escola, exigir-se-ia do alunado um papel ativo, criador, responsável e solidário. E assim, corroborando o pensamento complexo de Morin (2000), a autora continua afirmando que entende a criatividade também como "fruto de processos dialógicos, recursivos, auto-organizadores, emergentes e transcendentes, entre sujeito e objeto" (Moraes, 2015, p. 175).

Moraes (2015) considera a criatividade dentro da dinâmica do pensamento complexo como um novo modo de pensar e uma nova atitude frente a educação, não pretendendo propor métodos ou modos de fazer. São princípios que assumem a abertura e a flexibilidade compatíveis com as singularidades dos contextos e sujeitos, num desafio ao modo de pensar pragmático e prescritivo. Essa compreensão corrobora 
nossa perspectiva enquanto pesquisadoras da criatividade e favorece o entendimento acerca da docência dentro de um pensar complexo.

Temos ciência do quanto a escola acaba sendo reprodutora de conhecimento, autoritária e fragmentada em seu pensar e em seu fazer. Por isso, sobre todo educador pesa a necessidade de reconhecer a aprendizagem como fenômeno interpretativo da realidade, e isso, conforme nos diz Demo (2002), implica sua construção, desconstrução e reconstrução. Sob essa perspectiva, Moraes (2008, p. 242) nos chama a perceber o que os temas aqui tratados nos revelam:

Revelam também alguns parâmetros, princípios e valores significativos que podem servir para a reconfiguração de um novo cenário educacional e serem indutores de práticas pedagógicas mais dinâmicas, integradoras, complexas e holísticas que requerem por sua vez, uma maior clareza conceitual em relação ao conhecimento, à aprendizagem e à complexidade envolvida nos processos educacionais.

Embora o pensamento complexo não tenha uma metodologia específica, temos que nos abrir à compreensão do continium dos fenômenos educacionais e encontrar vias de promover práticas pedagógicas mais criativas e integradoras, a reposicionar o sujeito aluno como protagonista do seu saber, rompendo com configurações cristalizadas. Decorre daí a importância de uma visão complexa da realidade como "atitude epistemológica" (Moraes, 2015) funcionando como princípio que alimenta uma postura transdisciplinar capaz de promover um espaço de interconexão disciplinar, de compreensão e valorização da diversidade, pluralidade e multidimensionalidades humana que se concretizam em uma metodologia. São com esses fios que acreditamos ser possível tecer práticas pedagógicas mais emancipadoras, dinâmicas e integradoras.

\section{Percurso metodológico da pesquisa}

No percurso metodológico, mapeamos a trilha percorrida nesse artigo que ora apresentamos, ressaltando seu caráter qualitativo dado ao propósito de investigar as interações e as práticas de letramento no contexto da sala de aula. A abordagem qualitativa coloca a ênfase na compreensão e admite que a realidade é subjetiva e inatingível, por isso, seu foco está em compreender e interpretar em vez de apenas mensurar e procurar com isso indicar a realidade tal como ela é, ou seja, como é percebida.

Dessa forma, a metodologia para esta pesquisa está assentada no estudo de caso. Esta opção foi determinada, sobretudo pelo fato de o estudo de caso emergir como estratégia de investigação cujas características possibilitam um conhecimento mais apurado e abrangente sobre as relações estabelecidas entre professor e alunos em suas interações nas práticas de letramento.

Assim, primou-se pelo estabelecimento de um recorte que permitisse representar a multidimensionalidade do fenômeno, de forma que nos conduzisse a compreensão do objeto em seu contexto, iluminado pelos referenciais teóricos do pensamento complexo. 
As bases dessa abordagem ancoram-se na proposição de uma reforma do pensamento/ pensamento complexo (Morin, 2000, 2001, 2005), na transdisciplinaridade (Nicolescu, 2001) e pelos estudos da criatividade (Torre, 2005) e (Moraes, 2015). Os outros fios que juntamos nessa tessitura estão vinculados às práticas de letramento escolar, cujo caminho de investigação trilham pelos Novos Estudos do Letramento (NEL), fundamentados em Street (2014), Barton e Ivanic (2000), Rojo (2009), Soares (2003) Kleiman (2006), principalmente.

O lócus de pesquisa foi a Escola Paroquial Sagrado Coração de Jesus, uma escola estadual conveniada à uma instituição religiosa, localizada em Araguaína, estado do Tocantins. O corpus selecionado para esse estudo foi levantado através das transcrições das aulas observadas, das narrativas dos sujeitos em interação em sala de aula, professoras de Língua Portuguesa, denominadas por P1 e P2, e dos alunos da turma 06, selecionada para esse estudo, além da análise documental, de modo especial o PPP da escola e os relatórios dos projetos.

O objetivo foi captar as percepções de professoras e alunos em interações nas práticas de letramento em atividades cotidianas de sala de aula e nas ações dos projetos desenvolvidos pela escola, conseguidos através da triangulação das informações obtidas no cruzamento de perspectivas de diversos atores, diversos olhares sobre um tema ou ação. Ao estabelecermos pontos convergentes e divergentes, temos condições de maior clareza de compreensão sobre aquele objeto, aspecto que pretendíamos atingir ao cruzarmos as perspectivas dos alunos. Nesse processo, nosso foco esteve em tecer a trama que envolvia os dados empíricos e os conceituais levantados, e, para isso, foi preciso mergulhar nos dados e permitir que eles fossem a bússola do caminho, contando sempre com o apoio dos objetivos.

\section{Resultados e discussões}

\section{Práticas de letramento numa perspectiva transdisciplinar: concepções $\boldsymbol{e}$ contribuições para uma prática criativa e integradora.}

Aceitar o convite feito por Morin (2010) para pensar complexo, tomar consciência que tudo se liga a tudo, é compreender que a maneira de como nos relacionarmos com a vida, com as pessoas, com a natureza, com nosso lado espiritual; tudo depende do nosso modo de pensar, "dependem das representações internas que se revelam em nossas ações, enfim, em nossa maneira de ser e estar no mundo" (Moraes, 2008, p. 272).

Cientes ou não, participamos de uma rede interdependente que configura e é configurada na construção coletiva do social, podendo tanto nos referir na macroestrutura da sociedade como um todo, ou na parte como referência ao contexto escolar. É nessa interação recursiva indissolúvel entre indivíduos sociedade e cultura, ou no triângulo da vida como proposto por D'Ambósio (1997): “indivíduo, sociedade e natureza que implica a necessidade de um pensamento mais abrangente, um pensamento complexo".

A interação é, portanto, peça fundamental na engrenagem do conhecimento. Segundo Piaget (1967), o conhecimento não parte nem do sujeito, nem do objeto, mas da interação entre ambos. Assim também nesse paradigma educacional que emerge, amparado por esses referenciais teóricos, é preciso ampliar a visão para os diversos 
níveis de realidade, compreendendo que a aprendizagem não é decorrência direta do ensino, mas que está diretamente ligada às atividades realizadas pelo sujeito em processos de interação com outros sujeitos e com o meio, possibilitado por meio da linguagem, em processos dialeticamente complexos, que concebem o ser em sua inteireza.

Outro aspecto importantíssimo ligado à interação, aprendizagem e criatividade é a emoção. Para Maturana (2002) "não é a razão o que nos leva à ação, mas a emoção". E afirma que vivemos numa cultura que supervaloriza a razão, que gosta de dizer que se distingue dos outros animais pela sua capacidade racional. $\mathrm{O}$ autor segue afirmando que as emoções não são algo que obscurece o entendimento, não são restrições da razão: elas são dinâmicas corporais que especificam os domínios de ação em que nos movemos (Maturana, 2002).

Ser educador nesse contexto contemporâneo, implica em refletir sobre essas questões. É necessário e urgente, olhar para o processo de ensino e aprendizagem e objetivar a "inteireza humana, pensamentos, emoções, intuições e sentimentos estejam em constante diálogo em prol da evolução da consciência humana" (Moraes e Torre, 2004, p. 55). E nesse sentido, é fundamental considerar aspectos da formação docente, especialmente pela urgência que as diversas tensões no contexto social contemporâneo nos apresentam, demandas que, embora não sejam novas, requerem dos profissionais saber lidar com elas; isso implica, inclusive, melhor compreender o outro e o mundo, a começar pela compreensão de si mesmo.

No entanto, estudos apontam para as possibilidades de superação dessa realidade que tem na atitude transdisciplinar uma nova postura diante do que está posto no âmbito da sociedade. Essa postura, enfatizada por D'Ambrósio (1997, p. 80), "repousa sobre uma atitude aberta, de respeito mútuo e mesmo de humildade com relação a mitos, religiões e sistemas de explicações e de conhecimentos, rejeitando qualquer tipo de arrogância ou prepotência”.

Assim, nos parece fundamental alinhar às concepções postas a perspectiva de criatividade no âmbito educacional da RIEC, podemos então dizer que, feito as devidas referências à criatividade, numa perspectiva complexa e transdisciplinar, estas sinalizam caminhos, não apenas quanto às questões epistemológicas, como lançam luz ao contexto pedagógico, e, de modo especial, ampliam os horizontes de análises das práticas de letramento ao colocar em destaque o papel da interação em sala de aula.

Como 'seres do nosso tempo', revelamos em nossas ações e palavras os aspectos que nos constituem. A maior parte dos educadores de hoje ainda espelha uma escolarização tradicional, na qual foi formada. Muitos vivenciaram essa educação muitas vezes mecânica e esvaziada de sentidos. Ser 'autor de mudanças' exige dos professores o desenvolvimento de suas próprias habilidades, partindo da tomada de consciência sobre a mudança nas concepções do que é ensinar e do que é aprender. Essa aparente mudança traz em si um grande passo para a superação e reconstrução conceitual, provocando novas possibilidades, ressignificações e reorganizações; promovendo um novo olhar e, consequentemente, resultando uma nova atitude dentro da sala de aula. Moraes (2008b) enfatiza que esta reforma do ensino e do pensamento, conforme assevera Morin (2002), constituem um empreendimento histórico que deve originar-se a partir dos próprios educadores e não exteriormente.

As professoras e os alunos, em seus depoimentos, referiram-se a momentos de vivências acadêmicas que extrapolavam a perspectiva de papéis, tempos e espaços tradicionais de ensinar e aprender. Para elas, quando se amplia a possibilidade de 
relacionar, de trazer a realidade do aluno para mais perto da aula formal, estimulando a curiosidade e os questionamentos, buscando envolvimento e vínculos, a aprendizagem passa a ter muito mais significado. Ao considerar essas posturas docentes, mesmo que intuitivamente, as professoras faziam algumas rupturas com as práticas tradicionais, o que satisfizeram aos estudantes, incluindo, nesta condição, a dimensão do prazer e da sensibilidade. À primeira vista, tendências teóricas que revalorizam as dimensões não cognitivas aparecem nas práticas timidamente, porém respaldadas numa postura transdisciplinar, valorização que se contrapõe à dimensão imposta pelo paradigma da ciência moderna.

Frente aos desafios que se apresentam à docência hoje, a reintrodução do sujeito cognoscente nos parece ser o que move as lentes para enxergar igualmente os papéis dos sujeitos do processo de ensino e aprendizagem na escola: o professor e o aluno. Navas (2010) afirma que a aprendizagem não se realiza no cérebro, mas na pessoa inteira, em todas as suas dimensões e inter-relações, de forma que o aluno deixa de ser mero expectador, passivo de um saber que lhe é transmitido pelo professor e passa a ocupar seu lugar como autor de sua história e coautor de histórias de aprendizagens em sala de aula.

Nessa nova lógica, o saber não se transmite, se constrói em processos de intersubjetividades, constituindo um processo individual e coletivo de investigação, tirando o peso valorativo da mera memorização de conhecimentos e permitindo que os alunos dialoguem com o conhecimento.

Desta forma, analisando o perfil das docentes entrevistadas, estas afirmaram gostar do que fazem e justificaram sua escolha profissional por esta perspectiva, tendo ambas iniciado na docência antes mesmo de sistematizarem seus conhecimentos teóricos. Assim, a experiência prática precedeu a teórica, e, só após anos de trabalho como docente é que os saberes da academia foram fazer parte de suas vidas. É salutar observar os muitos momentos nos quais foram possíveis observar que a curva da trajetória de ambas professoras se tocara, mesmo considerando a diferença de idade e de tempo de trabalho no lócus pesquisado.

P1: Na verdade, a minha relação com a pedagogia começou bem antes da "pressão" do vestibular, pois naquela época tínhamos que decidir, ao concluir o Ensino Fundamental, se cursaríamos magistério, contabilidade ou colegial, fato que já pré-indicava o caminho que seguiríamos. A paixão por crianças, pela vivencia na escola e também a possibilidade de conseguir emprego de forma mais rápida foram alguns dos motivos que me levaram a escolher o magistério...

Durante os anos que trabalhei naquela escola vivenciei, sem ainda saber que existiam estudos nessa área, uma imersão no universo da afetividade. (grifo nosso).

P2: Ao terminar o ensino médio não foi possível fazer um curso superior, pois para isso teria que morar numa cidade a 1200 quilômetros de Araguaína e meus pais não tinham condições financeiras. Por isso fui trabalhar e parei de estudar. Casei, tive duas filhas e o que surgia como oportunidade eu aceitava. Trabalhei em casa veterinária, imobiliárias. 
Em sala de aula iniciei por acaso. Substituindo uma professora e gostaram do meu trabalho e fui ficando. Depois, resolvi fazer Faculdade de Letras, mais tarde, muito tempo mais tarde, acho que oito anos, fiz pós-graduação em psicopedagogia. Trabalho há muito tempo, tanto na escola pública quanto na particular. Na particular, hoje eu faço parte da coordenação.

Ser professora para mim é ter a capacidade de aprender sempre, é ser persistente e comprometida diante dos conflitos diários de uma sala de aula. E nesta relação aluno professor, faz-se necessário perceber no aluno um ser com experiências e importar com elas. Surge assim a afetividade, ingrediente indispensável em qualquer relacionamento, pois é através desse relacionamento que seremos respeitados.

A matriz que as professoras têm da docência tem raízes históricas e sociais, assentadas na construção das relações pelo viés da afetividade. Nesta condição, muito da construção do ensino que realizam nas suas práticas emergem na interação em sala de aula. Essa perspectiva, por si só já exige uma reconfiguração epistemológica, um pensar que favoreça o questionamento e a revisão constantes de nossas concepções e crenças, que valorize as diferentes dimensões humanas, capaz de apreender o mundo em sua totalidade e, ao mesmo tempo, manter-se eternamente aberto ao que está por vir (Morin, 2002).

Estiveram presentes nas falas das professoras e puderam ser observadas nas ações das mesmas em sala de aula, a valorização dos conhecimentos prévios dos alunos, sua crença sobre a afetividade na relação aluno - professor, cujo passo importante é perceber no aluno um ser com experiências.

... têm alguns (referindo-se aos professores de modo geral) que parece que tem medo de fugir um pouco ali daquela rotina, sabe? Daquilo que tá [sic] programado. Tem aquela ansiedade: vão me cobrar... o aluno tem que saber... ou ainda "será que vão achar que tô [sic] fugindo dos conteúdos?”(professora P2)

Como se pode perceber na fala da professora, muitas são as razões que podem levar os docentes a se afastarem da ideia de um trabalho que considere as experiências desse ser aluno. Isso exige uma postura de abertura, empatia e diálogo, de tirar de si e do aluno 'o medo de errar', ou medo de perder seu 'poder'. Assim, consideramos que o professor que conseguir praticar a empatia e estabelecer o diálogo terá mais acesso a perceber os obstáculos à sua aprendizagem, melhorando o "clima" da sala de aula (Moraes e Torre, 2004).

O ideal, mesmo que nem sempre fácil, como mencionado pela professora, é o que desejamos e o que urge na contemporaneidade: um processo de ensino e aprendizagem mais integrado. E o porquê, a própria professora $\mathrm{P} 1$ responde: porque o real é integrado, porque "um conteúdo tem relação com outro conteúdo, porque na vida tudo tem a ver com tudo, tudo se relaciona". Somos partes de um todo, de uma rede e, como bem resumiu Morin (2002), isso significa dizer que tudo está interligado, tudo o que acontece fora da sala de aula, tudo que pode ser considerado "externo" produz efeitos resultantes e interferentes no processo educativo, na maneira de estabelecer interação entre professor e alunos, enfim "nada é neutro" (Navas, 2010, p. 90). 
Na perspectiva da professora P1, na maioria das vezes, o fazer de muitos professores não muda porque não sabem como fazer, por mais que haja formação nessa direção, também há muita incoerência no sistema educacional.

Aqui eu tento na minha sala, me viro porque sou só com todas as disciplinas, por exemplo, e eles ((os alunos)) tão super envolvidos, lendo e pesquisando, mas aí lá no sexto ano, mesmo tendo o projeto, muita gente não abraça essa prática e, às vezes, eu vejo que não faz porque não sabe, entendeu?

Sou consciente de uma nova postura diante do conhecimento, uma mudança de atitude em busca do contexto do conhecimento, em busca do ser como pessoa integral, que visa garantir a construção de um conhecimento globalizante, rompendo com os limites das disciplinas... Apesar de receber constantemente formação incentivando essa prática, como também favorecer a aprendizagem pela descoberta, metodologia de projetos etc...vivo numa incoerência muito grande, onde o mesmo sistema que incentiva essas práticas é quem dificulta o " colocar em prática", já que temos uma grande curricular que delimita uma quantidade $\mathrm{x}$ de aulas de cada disciplina, um horário de aula que determina que o professor deve trabalhar 5 disciplinas diariamente, planejamento e diário acompanhado que deve contemplar os conteúdos já estabelecidos para cada bimestre (professora P1).

A percepção da professora sobre a incoerência do sistema educacional revela uma visão complexa que emerge da sua realidade prática. Esta capacidade auto questionadora, auto-reflexiva de quem é capaz de mudar a forma como se olha para os problemas, faz toda a diferença sobre as escolhas a serem feitas, e é nesse ponto que as mudanças acontecem. Essa clareza ao olhar as conexões construídas pelos paradigmas tradicionais da ciência com suas contribuições e limitações ativam a possibilidade de um 'pensar sobre o pensar', e, no caso dos educadores, possibilita um repensar nas práticas, do seu fazer local sob a perspectiva de interdependência com seu contexto maior.

As rodas de leitura e rodas de conversa foram evidenciadas como integrantes das práticas que trazem o aspecto da corporeidade e da oralidade para a cena, promovendo uma maior interação em sala de aula, no entanto, evidenciamos também que esses eventos aconteciam um pouco desvinculados do restante das atividades, sendo essa a maior dificuldade encontrada e já descrita pela professora, articular ações dos projetos aos conteúdos cobrados pelo currículo formal, posto que essas corriam paralelo às demais atividades.

Essa é uma dificuldade que acaba sendo da maioria das escolas: lidar com o tempo escolar e os desafios de "dar conta" de inovar ou trabalhar mais articulado, quando há um programa escolar a cumprir. Na maioria das vezes, a necessidade de cumprir prepondera e, nessa trajetória, dividem-se os caminhantes. Os obstinados perseveram, buscando alternativas; outros encontram no obstáculo "respaldo" para a marcha lenta das mudanças que tanto se quer ver na educação. De certo modo, há algumas visões também cristalizadas em muitas pesquisas que colocam a carga de 
mudança toda no professor e acabam também por contribuir com o sentimento de angústia ou até mesmo frustração em relação a si mesmo, ou ao ensino.

Apesar de toda essa problemática mais ou menos generalizada, conforme nos assegura Torre $(2009$, p. 21$)$, "há que se reconhecer que estamos num momento de transição" e tal como um preceito bem pertinente a esse momento, a consciência da realidade traz em si uma mudança de percepção dessa realidade e por conseguinte, conforme apontado por Arnt (2010, p. 132) "em ambiente de aprendizagem, o nível de consciência de cada um de nós pode ser dado pela integração do nosso nível de percepção em consonância com nosso nível de expressão", daí a importância de valorizar momentos de formação com oportunidades de reflexão na ação, como possibilidade de ampliar nossa percepção e condições de iluminar a nossa prática, nosso cotidiano, nos dando elementos capazes de fomentar ações sem a necessidade de entrar no jogo da fragmentação ou redução, sempre atentos ao papel que temos quando ampliado nosso nível de consciência, que possuímos mais elementos para conhecer a realidade estabelecendo pontes com nosso cotidiano, dando novo sentido ao nosso fazer, ressignificando nossa prática (Arnt, 2010).

Outro aspecto a ser destacado diz respeito à criatividade da professora $\mathrm{P} 2$ na organização espacial da sala de aula, compostas por salas apertadas e quentes, onde mal se podia caminhar entre as carteiras, de modo intencional, com objetivo de melhorar o ambiente de aprendizagem, a professora P2 encontrou na disposição das carteiras uma forma de se integrar mais com os alunos, ao mesmo tempo que tirava do foco os problemas com o espaço. Organizava formatos variados mesmo quando o trabalho não tinha finalidade de ser coletivo. Variando os formatos, ora em U, ou filas lado a lado, às vezes frente a frente, assumindo que, na maioria das vezes, seu objetivo era apenas um jogo com a sensação do espaço. "Só mesmo para a questão de eles sentirem algo de diferente, eu falo assim: 'gente, olha, vamos organizar as carteiras assim, hoje...pra nós nos enxergarmos diferentes'. E isso pode parecer nada, mas faz muita diferença". As afirmações da professora P2 evidenciaram sua consciência do efeito dos arranjos sobre as sensações e estímulos dos alunos, numa demonstração de uso consciente do espaço para a organização das interações, focando na disposição diferenciada e nas atividades, suavizando a falta de espaço e o calor intenso da sala cheia.

... ah... e tem o 'lance' das carteiras...(risos). Você já viu, né? (se referindo à pesquisadora)Você já viu o que ela faz com as carteiras... Achei muito legal que no primeiro dia de aula ela fez uma forma de labirinto e ela disse que era porque ficava melhor pra ela caminhar no meio da turma, esse dia foi o melhor pra mim... fiquei surpresa...achei muito massa esse jeito." (Aluna A. A.).

De acordo com Teixeira e Reis (2012, p. 164) "a flexibilidade na colocação das carteiras e das mesas e no agrupamento dos alunos assume um papel muito importante quando se considera o uso do espaço na sala de aula". Ele deve ser estimulante, rico em informações e ter como objetivo central propiciar uma maior interação entre as pessoas. Zabalza (1998, p. 236) define este ambiente como espaço "constituído como uma estrutura de oportunidades". De modo especial para aqueles professores que buscam propostas educativas mais dialógicas e integradoras esse já se mostra um passo significativo no percurso. 
Esses são exemplos das emergências peculiares ao exercício da docência em sala de aula, emergências que exigem um olhar atento e sensível por parte do docente (Moraes, 2008). É a sensibilidade que ajuda a romper a lógica do ser e do saber, consequentemente, será preciso compreender também que "usamos todos os nossos sentidos e diferentes formas de pensamento e imaginação no processo de aprendizagem. Quando isso acontece a aprendizagem é relevante, significativa e integradora" (Moraes e Torre, 2004, p. 83).

Esse modo de proceder da professora pode ser considerado de atitude criativa, pois criou uma possibilidade diante da adversidade vivenciada. Uma ação inicialmente intuitiva, mas que, possibilitou à professora, pela sensibilidade, perceber o quanto aquela simples ação se tornava importante, estabelecendo maior qualidade aos vínculos entre a professora e os alunos. Desta maneira, podemos inferir que a sensibilidade e o cuidado também são gatilhos capazes de gerar atitudes criativas e transdisciplinares onde se captem fenômenos nos quais o corpo e as sensações se tornam bastante relevantes para a ação de educar, promovida na empatia.

A interação estabelecida especialmente nos eventos de letramento observados revelaram o interesse da professora pelo ser aluno, buscando fortalecer autoestima pelo conhecimento que o aluno já trazia, ajudando na criação de vínculos e no fortalecimento da confiança, além de promover a participação ativa na aprendizagem. Essa postura regular e repetida, observáveis nos eventos mediados pelos textos, condiz com o que Barton e Ivanic (2000) apresentam como práticas de letramento. Esses mesmos autores chamam a atenção para a observação das práticas para poder perceber as relações de poder e hierarquia constituída.

Nessa relação com vínculos estabelecidos no diálogo e na empatia, foi possível perceber uma busca pela quebra da centralização de poder do professor, postura que já não responde mais às necessidades contemporâneas. Confirmando o que Navas (2010) afirma sobre o fato de a aprendizagem não se realizar no cérebro, mas na pessoa inteira, em todas as suas dimensões e inter-relações. Assim, quanto mais os professores souberem como seus alunos usam o texto escrito para aprenderem e para se inserirem no mundo, mesmo no digital, mais expressivas as práticas de letramento ocorrerão. Da mesma forma, quanto mais os professores lidarem com diferentes formas de uso da leitura e da escrita para construção de sentido, tanto mais significativos e próximos da realidade dos estudantes os eventos de letramento estarão.

\section{Considerações finais}

Caminhar à luz do pensamento complexo, trouxe-nos a compreensão sobre a urgência e ao mesmo tempo a dificuldade de rompermos com os paradigmas tradicionais arraigados em práticas fragmentadoras. Essa noção está intimamente ligada a forma como pensamos e nossa visão de mundo. Por isso, é uma mudança que não se dá de fora para dentro.

Trouxe-nos a clareza de que ter consciência da necessidade da mudança já é o primeiro passo, porém a caminhada pode avançar mais se, juntamente a essa compreensão, entendermos que não é sobre adotar uma 'metodologia ativa', para usar o termo do momento, se, no nosso ser, a postura verticalizada de dono do saber impera, tanto diante do conhecimento como diante dos alunos. 
Em nosso estudo de caso, a afetividade figurou como elemento estruturante e significativo em todos os componentes de análise, por isso seu destaque nessas considerações finais, visto que, do PPP às práticas das professoras colaboradoras, ficou evidenciado que sua presença não era meramente intuitiva a depender do perfil dos professores, mas fazia parte, intencionalmente, do desenvolvimento de um trabalho centrado em despertar a confiança, elevar a autoestima, resgatar os valores humanos, ou seja, estabelecer no trajeto, vínculos pela empatia e promover o necessário diálogo.

Nesse aspecto, sustentamos que a relevância dos resultados desta pesquisa gera a expectativa de que gestem novas ações, reflexões e pesquisas que possam contribuir com as atuais demandas acadêmicas e sociais, que são muitas, e se apresentam diante de nós, especialmente em tempos de retrocessos como os que vivenciamos no atual cenário político e educacional brasileiro. Por isso, mais urgentes e relevantes se apresentam na confirmação da tese que defendemos, que é possível, a partir das ações cotidianas, em iniciativas de criação de vínculos na relação professor e aluno, promover um fazer mais criativo e integrado, capaz de contribuir efetivamente para ações transformadoras. Pode parecer uma ação simples, mas demanda um pensar complexo, capaz de promover uma 'consciência humana' e 'uma postura transdisciplinar' que perceba e valorize o conhecimento a partir das dimensões subjetivas do ser humano, as quais são negadas no paradigma tradicional.

\section{Referências}

Arnt, R. M. (2010). Formação de professores e didática transdisciplinar. In: M. C. Moraes e J. M. B. Navas (Org.). Complexidade e transdisciplinaridade em educação: teoria e prática docente (pp. 109-135). Rio de Janeiro. Wak.

Bunzen, C. S. (2009). Dinâmicas discursivas na aula de português: os usos do livro didático e projeto didáticos autorais. Tese (Doutorado em Linguística Aplicada) Campinas: Universidade Estadual de Campinas.

D’Ambrosio, U. (1997) Transdisciplinaridade. São Paulo: Palas Athena.

Demo, P. (2002). Complexidade e aprendizagem: a dinâmica não linear do conhecimento. São Paulo: Atlas.

Kleiman, A. B. (2006). Leitura e prática social no desenvolvimento de competências no ensino médio. In: C. Bunzen e M. Mendonça (Orgs.). Português no ensino médio e formação do professor (pp 23-36). São Paulo: Parábola Editorial.

Maturana, H. (2002). Emoções e linguagem na educação e na política. Belo Horizonte: UFMG.

Moraes, M. C. (2008). Pensamento eco-sistêmico: educação, aprendizagem e cidadania no século XXI. Rio de Janeiro: Vozes.

Moraes, M. C. e Navas, J. M. B. (Colab.) (2015). Transdisciplinaridade, criatividade e educação: fundamentos ontológicos e epistemológicos. São Paulo: Papirus.

Moraes, M. C. e Torre. S. (2004). Sentipensar: fundamentos e estratégias para reencantar a educação. Petropolis: Vozes.

Morin, E. (2000). Os sete saberes necessários à educação do futuro. (2a ed.). São Paulo: Cortez. 
Morin, E. (2001). Introdução ao pensamento complexo. ( $3^{\mathrm{a}}$ ed.). Lisboa: Instituto Piaget.

Nicolescu, B. (2001). O manifesto da transdisciplinaridade. (2 ${ }^{\mathrm{a}}$ ed.). São Paulo: Triom.

Santos. A. e Sommerman. A. (2014). Ensino disciplinar e transdisciplinar: uma coexistência necessária. Rio de Janeiro: Wak.

Street, B. (2014). Letramentos sociais: abordagens críticas do letramento no desenvolvimento, na etnografia e na educação. São Paulo: Parábola Editorial.

Teixeira, M. T. e Reis, M. F. (2012). A organização do espaço em sala de aula e suas implicações na aprendizagem cooperativa. Meta: Avaliação. 4(1), 162-187).

Torre, S. (2009). Um olhar ecossistêmico e transdisciplinar sobre a educação: olhar o futuro com outra consciência. In M. Zwierewicz e S. de la Torre. (Coord.). Uma escola para o século XXI: escolas criativas e resiliência na educação (pp. 17-28). Florianópolis: Insular. ' Submissão feita ao Comitê de Ética em Pesquisa - CEP da Universidade Federal do Tocantins - UFT,
aprovado em parecer sob número 1.742.116.

Data da recepção: 17/09/2019

Data da revisão: 21/10/2019

Data do aceite: 23/10/2019 